\title{
Factors Associated with Longer Length of Stay in Recurrent Cellulitis on Lower Legs
}

\author{
Vesna Brishkoska-Boshkovski ${ }^{1 *}$, Mirela Vasileva ${ }^{2}$, Marjan Baloski $^{3}$ \\ ${ }^{1}$ Department of Dermatology, City General Hospital " $8^{\text {th }}$ September" Skopje, Republic of Macedonia; ${ }^{2}$ Department of \\ Dermatology, Clinical Hospital Shtip, Shtip, Republic of Macedonia; ${ }^{3}$ Department of Pulmonology and Allergology, City General \\ Hospital "8" September" Skopje, Republic of Macedonia
}

\begin{abstract}
BACKGROUND: Cellulitis is a common infectious disease with typical feature - the tendency for recurrence.

AIM: The aim of the study was to define comorbidities, clinical, and laboratory - biochemical factors associated with longer length of stay (LOS) in patients with recurrent cellulitis in the lower legs.

MATERIALS AND METHODS: The study is a retrospective-cohort study conducted at the Department of Dermatovenerology at General Hospital in Skopje, from January 2016 to August 2019. In the study, we included and analyzed only hospitalized patients admitted for recurrent cellulitis on the lower legs. Inclusion in the study recorded the following variables - comorbid conditions in the patients - present in the medical records or obtained from the interview of the patient and initial values of laboratory assays on admission.

RESULTS: The study included hospitalized 205 patients, admitted for recurrent cellulitis. The most significant comorbid conditions and laboratory parameters which correlate with increased LOS are as follows: Type 2 diabetes mellitus - insulin dependent $(p<0.001)$, chronic renal failure $(p=0.003)$, ischemic heart disease $(p=0.006)$, peripheral arterial disease $(p=0.007)$, fever $\geq 38.0^{\circ} \mathrm{C}(p<0.001)$, hypoalbuminemia $<34 \mathrm{~g} / \mathrm{L}(\mathrm{p}<0.001)$, elevated value of C-reactive protein $>10 \mathrm{mg} / \mathrm{L}(p<0.001)$, and leukocytosis $>10^{9} \mathrm{~L}(p=0.009)$.

CONCLUSION: Cellulitis is potential medical emergency event. Recurrence is the most significant complication of cellulitis and lower legs cellulitis is associated with a risk for long-term morbidity. The study has identified severa independent factors that are significantly associated with an increased LOS. This independent factors present on admission can stratify the patient with the highest risk of mortality, can improve patient care for better outcomes, and decrease the number of relapses and hospital readmissions.
\end{abstract}

Edited by: Sasho Stolesk Citation: Brishkoska-Boshkovski V, Vasileva M Baloski M. Factors Associated with Longer Length of Stay in Recurrent Cellulitis on Lower Legs. Open Access Maced J Med Sci. 2020 May 05; 8(B):490-494. https://doi org/10.3889/oamjms.2020.4074 Keywords: Length of stay; Recurrent cellulitis; Diabetes
mellitus - insulin dependen Department of Dermatology, City General Hospital $8^{\text {th }}$ Sempember" Skopje, Republic of Macedonia. E-mail: vbrishkoska@yahoo.com Received: 17-Nov-2019 Revised: 21-Jan-2020
Accepted: 07-Mar-2020 Copyright: ๑ 2020 Vesna Brishkoska-Boshkovski, Mirela Vasileva, Marjan Balosk Funding: This research did not receive any financia Competing Interests: The authors have declared that no competing interest exists Open Access: This is an open-access article distribute
under the terms of the Creative Commons AttributionNonCommercial 4.0 International License (CC BY-NC 4.0)

\section{Introduction}

Cellulitis is a soft-tissue infection that affects the deep dermis and subcutaneous tissue and erysipelas is a common bacterial infection that affects the more superficial layers [1], [2]. Still, cellulitis can extend to the superficial and erysipelas to the deeper layers of the skin, and in many cases, both conditions accompany each other and it is impossible to make a significant distinction [3]. Nowadays, the erysipelas considers itself a form of cellulitis and not a separate entity [3].

The traditional teaching is that most commonly, cellulitis is caused by beta-hemolytic streptococcus (BHS) [4]. In its classical form is considered to be exclusively caused by Beta hemolytic Streptococcus (BHS) and most commonly Group A streptococcus (GAS) [1], [4]. BHS other than GAS may be associated with cellulitis - most commonly the $G$ group [4]. Less frequently Group B is isolated from cases of acute and recurrent cellulitis [4]. Other than BHS, cellulitis somewhat is less frequently caused by Staphylococcus aureus [4].
Cellulitis most commonly is located on the lower legs [1], [2], [4]. The diagnosis is primary clinical and is based empirically on the cutaneous manifestations and systemic signs of infection [4]. The lower leg cellulitis has a distinct feature, that is, the tendency to reoccur. The incidence of recurrent cellulitis varies from study to study. The relapse rate is $8-20 \%$ per year [5]. In the study of Pavlotsky et al., a retrospective 3-year study there is a significantly higher relapse rate (higher than 45\%) [6]

Several major retrospective studies have analyzed the epidemiology of cellulitis in the antibiotic era. In all of them, the incidence is markedly increased [5], [6], [7]. In the Dutch study of Goettsch et al., there was an overall increase in the number of hospitalizations per year [7]. The incidence increased from 1.7 to 22/1000 population between 2001 and 2006 years, and an average of $7 \%$ of all patients with cellulitis being hospitalized [7]. This study analyzed the increased incidence, which correlated primarily with age, namely, it was 5 times higher in older patient group, 54-85 years [7]. The analysis has shown that an additional reason for the increase in the incidence is the increase of the population with various causes 
of immunosuppression [7]. In the present time, the incidence of cellulitis is thought to be 200/100,000 people per year, and it was observed most commonly in the oldest age groups [5].

The trend of increasing incidence is also seen in the increased number of hospitalizations for this disease in several global studies. A 2012 study of Phoenix et al. in the United States showed an increase rate in hospitalizations from 17.3 to $32.5 / 1000$ residents a year, resulting in as many as 600,000 hospitalizations in 2010 or $3.7 \%$ of all hospitalizations in the emergency departments [8]. Cellulitis is a common disease whose incidence is increasing and is thought to be $10 \%$ of all infectious diseases associated with hospitalization in the United States [9]. In the UK, cellulitis is the primary diagnosis in 114,190 consultations in secondary health care and 75,838 hospitalizations with an average length of hospital stay of 3 days, and average age of the patients is 63 years [10]. In Australia, the number of hospitalizations has grown to $11.5 / 10,000$ population (2001-2002) with an average hospital stay of 5.9 days [11].

In this study, we analyzed risk factors associated with prolonged hospital stay in recurrent cellulitis. Accurate and precise identification of the risk factors will have significant implications for reducing morbidity of this disease, better therapeutic management, and stimulate the creation of appropriate preventive measures, especially in the patients with highest risk.

\section{Methods}

This retrospective population-based, cohort study was conducted in the Department of Dermatology at General Hospital in Skopje. We included all patients above 18 years who were admitted to the hospital with primary diagnosis of recurrent cellulitis of the lower legs between January 2016 and August 2019. All types of necrotizing skin and soft-tissue infections, skin infections in severe immunocompromised patients, post-operative wound infections, necrotizing fasciitis, and admissions where cellulitis of the lower legs was a secondary diagnosis have been excluded from the study.

We analyzed only the data of the hospitalized patients with recurrent cellulitis, defined as a second/ multiple episode of cellulitis which occurs on the same anatomical localization of the previous episode, at least 1 month-1 year from the initial diagnosis. The analyzed data included:

Initial values of laboratory assays (leukocytes, granulocytes, platelets, erythrocyte sedimentation rate [ESR], and C-reactive protein [CRP]). Serum levels of glucose, transaminase, urea, creatinine, and albumin. The initial value of fibrinogen as an acute-phase protein was also recorded.
Comorbid conditions in the patients - present in the medical records or obtained from the interview of the patient (obesity - calculation of body mass index), diabetes mellitus (D.M), chronic kidney failure, chronic lung disease, hepatic cirrhosis, congestive heart failure and ischemic heart disease, cerebrovascular disease, addictions, chronic pulmonary disease, diseases of the thyroid gland, history of malignancy, rheumatic diseases, autoimmune diseases, immunosuppression, presence of an chronic ulcer, chronic venous insufficiency, and peripheral arterial occlusive disease.

Regarding statistics, Kolmogorov-Smirnov test was used to test the distribution of data. The categorical variables are represented by distribution on frequencies. Quantitative variables with symmetric distribution are shown with mean values, and the mediana was used to display quantitative data with asymmetric distribution. Student's t-test for independent samples and MannWhitney U-test were used to compare groups with first episode and recurrent cellulitis. The statistical significance was defined on level of $p<0.05$.

\section{Results}

A total of 428 patients were hospitalized for acute cellulitis of the lower legs, but 205 of them were admitted for recurrent cellulitis. Table 1 displays the distribution of the hospitalized patient in two groups patients with recurrent cellulitis - 205 patients and first episode cellulitis (non-recurrent cellulitis) 223 patients, the mean value and median of the length of stay (LOS).

Hospitalized patients with recurrent cellulitis had an average hospital stay of $8.81 \pm 4.9$ days, and patients without recurrence had an average LOS of $7.71 \pm 4.3$ days. According to median values, half of patients with relapse were hospitalized for more than 8 days and half of patients without relapse for more than 7 days. Statistical analysis confirmed that patients with recurrent cellulitis had significantly longer LOS than patients with first episode of cellulitis $(p=0.01)$ (Table 1).

Table 1: LOS in both recurrent and first episode cellulitis

\begin{tabular}{llllll}
\hline Type of cellulitis & \multicolumn{3}{l}{ Descriptive statistics (LOS) } & p-level \\
\cline { 2 - 5 } & $\mathrm{n}$ & Mean \pm SD & Min-Max & Median (Q25-75) & \\
\hline Recurrent cellulitis & 205 & $8.81 \pm 4.9$ & $2-30$ & $8(6-10)$ & $\mathrm{Z}=2.5$ \\
Non recurrent cellulitis & 223 & $7.71 \pm 4.3$ & $1-28$ & $7(5-9)$ & $\mathrm{p}=0.01$ \\
\hline Mann-Whitney test, LOS: Length of stay. & & & &
\end{tabular}

Figure 1 shows a graphical representation of the length of stay of the two groups of respondents, which demonstrated statistical significance in the group of recurrent cellulitis.

Table 2 displays the LOS (mean values and median) in patients with recurrent cellulitis in correlation with the comorbid conditions of the patients. 


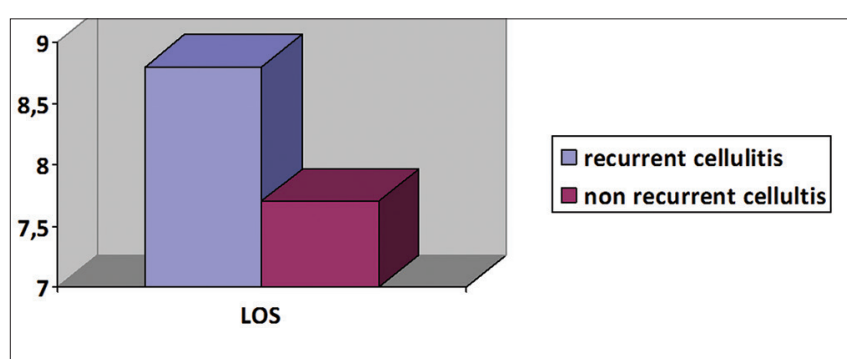

Figure 1: Distribution of length of stay in the two groups of patients

The most significant comorbidity associated with increased LOS in patients with recurrent cellulitis is insulin-dependent D.M. $(p<0.001)$, with an average length of hospital stay $-10.05 \pm 5.7$. Recurrent cellulitis in patients with chronic kidney failure has an average hospital stay of $12.24 \pm 5.5$ which strongly correlates with increased LOS $(p=0.003)$. Positive association of recurrent cellulitis with increased LOS is evident in patients with ischemic heart disease $(p=0.006)$, peripheral artery occlusive disease $(p=0.007)$, hepatic cirrhosis $(p=0.038)$, and patients with chronic ulcer $(p=0.03)$.

Table 2: LOS in recurrent cellulitis and correlation with comorbidities

\begin{tabular}{lllll}
\hline Variable & $\mathrm{n}$ & $\begin{array}{l}\text { Mean } \pm \\
\mathrm{SD}\end{array}$ & Min-Max & $\mathrm{p}$-value \\
\hline Obesity (body mass index $>30 \mathrm{~kg} / \mathrm{m}^{2}$ ) & 124 & $8.24 \pm 4.1$ & $2-24$ & $\mathrm{NS}$ \\
Insulin dependent diabetes mellitus & 80 & $10.05 \pm 5.7$ & $2-30$ & $<\mathbf{0 . 0 0 1}$ \\
Diabetes mellitus on oral hypoglycemic agents & 49 & $8.21 \pm 3.7$ & $2-17$ & $\mathrm{NS}$ \\
Chronic kidney failure & 21 & $12.24 \pm 5.5$ & $2-24$ & $\mathbf{0 . 0 0 3}$ \\
Hepatic cirrhosis & 8 & $10.75 \pm$ & $3-17$ & $\mathbf{0 . 0 3 8}$ \\
& & 4.9 & & \\
History of malignancy & 23 & $9.26 \pm 5.20$ & $2-22$ & $\mathrm{NS}$ \\
Autoimmune disease & 21 & $8.95 \pm 4.2$ & $3-20$ & $\mathrm{NS}$ \\
Alcoholism & 14 & $8.79 \pm 2.9$ & $5-14$ & $\mathrm{NS}$ \\
Iv drug addiction & 1 & $7.0 \pm 0$ & 7 & $\mathrm{NS}$ \\
Active smoking & 59 & $9.02 \pm 5.4$ & $3-30$ & $\mathrm{NS}$ \\
Rheumatism & 40 & $8.52 \pm 3.8$ & $3-21$ & $\mathrm{NS}$ \\
Hypothyroidism & 19 & $8.63 \pm 4.7$ & $3-20$ & $\mathrm{NS}$ \\
Hyperthyroidism & 3 & $8.0 \pm 2.0$ & $6-10$ & $\mathrm{NS}$ \\
Cerebro-vascular disease & 25 & $7.8 \pm 4.2$ & $3-21$ & $\mathrm{NS}$ \\
Chronic pulmonary disease & 20 & $7.95 \pm 4.9$ & $2-24$ & $\mathrm{NS}$ \\
Congestive heart failure & 64 & $7.72 \pm 3.9$ & $2-22$ & $\mathrm{NS}$ \\
Ischemic heart disease & 25 & $11.48 \pm 6.5$ & $4-28$ & $\mathbf{0 . 0 0 6}$ \\
Immunosuppression & 30 & $8.7 \pm 3.7$ & $3-20$ & $\mathrm{NS}$ \\
Chronic ulcer & 70 & $9.7 \pm 5.5$ & $2-30$ & $\mathbf{0 . 0 3}$ \\
Chronic venous insufficiency & 91 & $7.7 \pm 3.9$ & $2-24$ & $\mathrm{NS}$ \\
Peripheral artery disease & 93 & $9.6 \pm 5.05$ & $2-28$ & $\mathbf{0 . 0 0 7}$ \\
\hline
\end{tabular}

Table 3 shows the correlation between increased LOS in recurrent cellulitis with systemic sign and laboratory analyzes (markers of inflammation and biochemistry markers).

Table 3: LOS in recurrent cellulitis and correlation with systemic signs and lab analyzes

\begin{tabular}{lllll}
\hline Variable & $\mathrm{n}$ & Mean $\pm \mathrm{SD}$ & Min-Max & $\mathrm{p}$-value \\
\hline Body temperature $\geq 38^{\circ} \mathrm{C}$ & 58 & $11.5 \pm 5.7$ & $4-30$ & $<0.001$ \\
Albumin level $<34 \mathrm{~g} / \mathrm{L}$ & 60 & $11.2 \pm 6$ & $3-30$ & $<\mathbf{0 . 0 0 1}$ \\
Fibrinogen $>4 \mathrm{~g} / \mathrm{L}$ & 150 & $9.4 \pm 5.1$ & $2-30$ & $\mathbf{0 . 0 5}$ \\
C-reactive protein $>10 \mathrm{mg} / \mathrm{L}$ & 187 & $9.05 \pm 5$ & $2-30$ & $<0.001$ \\
Leukocytosis $>10^{9}$ & 103 & $10.2 \pm 5.6$ & $2-30$ & $\mathbf{0 . 0 0 9}$ \\
Erythrocyte sedimentation rate $>10 \mathrm{~mm} / \mathrm{h}$ & 173 & $8.9 \pm 4.9$ & $2-30$ & $\mathrm{NS}$ \\
\hline
\end{tabular}

Fever $\geq 38^{\circ} \mathrm{C}$ in patients with recurrent cellulitis has a very strong correlation with increased LOS $(p<0.001)$. These patients had an average hospital stay $11.5 \pm 5.7$. The markers of inflammation - elevated CRP level $(>10.0 \mathrm{mg} / \mathrm{L})$, leukocytosis $\left(>10^{9}\right)$, and serum fibrinogen level $>4 \mathrm{~g} / \mathrm{L}$, in recurrent group had a very strong positive correlation with LOS, $p<0.001$, $p=0.009$, and $p=0.05$, respectively. Hypoalbuminemia $<34 \mathrm{~g} / \mathrm{L}$ in recurrent cellulitis was also associated with $\operatorname{LOS}(<0.001)$.

\section{Discussion}

Patients with recurrent cellulitis have a longer LOS. Patients with recurrence had a mean LOS $8.81 \pm$ 4.9 days versus $7.71 \pm 4.3$ in the non-recurrent group, which was statistically significant $(p=0.01)$.

The LOS in recurrent cellulitis, in the study, was associated with certain comorbidities and laboratory-biochemical factors - D.M. insulin dependent $(p<0.001)$, ischemic heart disease $(p=0.006)$, chronic renal failure $(p=0.003)$, hepatic cirrhosis $(p=0.038)$, fever $\geq 38.0^{\circ} \mathrm{C}(p<0.001)$, hypoalbuminemia $<34 \mathrm{~g} / \mathrm{L}$ $(p<0.001)$, fibrinogen value $>4 \mathrm{~g} / \mathrm{L}(\mathrm{p}=0.05)$, elevated value of CRP $>10 \mathrm{mg} / \mathrm{L}(p<0.001)$, leukocytosis $>10^{9} \mathrm{~L}$ $(p=0.009)$, chronic ulcer $(p=0.03)$, and peripheral arterial disease $(p=0.007)$. Karppelin et al. in a study from 2010 also suggested that recurrent cellulitis has more difficult presentation which, in this study, was associated with the higher level of CRP, leukocytes, and granulocytes, duration of fever, and length of hospital stay [12]. In this study, D.M. type 2 is associated with prolonged hospital stay [12]. The mean LOS was 12.9 and 9.4 days, respectively, in patients with and without D.M. $(p=0.064$ marginally significant), indicating a higher hospital cost in patients with D.M. [12].

In a study by Carratala et al., hypoalbuminemia and renal insufficiency were identified as a risk factor for prolonged hospitalization in patients with cellulitis [13]. In this study, length of hospital stay is associated with following factors - age, hypoalbuminemia, and DM [13].

Infectious episodes of cellulitis are usually associated with significant clinical and biological signs of inflammation, such as fever, elevated markers of inflammation - serum levels of fibrinogen, and CRP, which were statistically analyzed and significantly associated in our study. Fever is not a consistent clinical feature and yet the absence should not preclude the diagnosis of cellulitis [4]. In our study, the mean values of the body temperature in the recurrent group were $37.22 \pm 0.9$ and $36.93 \pm 0.7$ in the non-recurrent group, respectively. The difference of slightly less than half a degree was statistically confirmed as significant $(p=0.00005)$. Fever often precedes any sign of skin inflammation and it is an important systemic feature in some patients [4].

We did not examine the association between clinical types of cellulitis with LOS, but Guberman et al., in a retrospective study from 1999 for bullous cellulitis in the lower legs, found that the median duration of 
hospitalization in patients with bullous cellulitis was significantly longer than in patients with non-bullous cellulitis [14].

In our study, the initial values of CRP were higher than the reference value in the majority of patients in both groups, but significantly more frequently in patients with recurrent cellulitis $-83.4 \%$ versus $69.05 \%$ $(p=0.000096)$. Patients with recurrent cellulitis had higher values of CRP from patients without recurrence $(p=0.000009)$. The mean and median values of this inflammatory parameter were $60.9 \pm 62.1$ and 33.6 in the recurrent group and $42.03 \pm 50.8$ and 20.85 in the nonrecurrent group, respectively. In the study of Chelsom et al., since 1994, it has been reported that CRP levels above > $200 \mathrm{mg} / \mathrm{L}$ is an indication for hospitalization and a high risk for developing necrotizing fasciitis [15].

\section{Conclusion}

The value of CRP, fever, and elevated serum level of fibrinogen correlates with LOS and disease severity. The value of CRP is a reflection of the severity of infection, which correlates with other studies of recurrent cellulitis [5], [6], [13]. In the study of Lazzarini et al., the mean CRP and ESR in the more severely ill group, with longer hospitalizations, was $100 \mathrm{mg} / \mathrm{L}$ and $70 \mathrm{~mm} / \mathrm{h}$, compared to $40 \mathrm{mg} / \mathrm{L}$ and $50 \mathrm{~mm} / \mathrm{h}$ in the shorter hospitalization group [16]. In a retrospective study by Concheiro et al., the same association was statistically confirmed, namely, longer hospital stay is associated with mean $\mathrm{ESR}=50 \mathrm{~mm} / \mathrm{h}$ and mean $\mathrm{CRP}=78 \mathrm{mg} / \mathrm{L}$ [17].

These results in terms of clinical and laboratory characteristics are consistent with a number of studies [5], [6], [12], [18], [19] that analyze risk factors for recurrent cellulitis of lower legs and indicate a high degree of clinical and biological inflammation.

In conclusion, the study has shown several risk factors that are associated with an increased LOS in patients with recurrent cellulitis. Hospital admission for recurrent cellulitis may be associated with considerable morbidity and mortality. This study allows us to determine and define high-risk patients present on admission, to ultimately improve patient care for better outcomes and decrease the number of relapses and hospital readmissions.

\section{References}

1. Bisno AL, Stevens DL. Streptococcal infections of skin and soft tissues. N Engl J Med. 1996;334(4):240-5. https://doi. org/10.1056/nejm199601253340407

PMid:8532002
2. Swartz MN. Clinical practice. Cellulitis. $N$ Engl J Med. 2004;350(9):904-12.

PMid: 14985488

3. Hay RJ, Adriaans BM. Bacterial infections. In: Burns DA, Breathnach SM, Cox NH, Griffiths CE, editors. Rook's Textbook of Dermatology. $7^{\text {th }}$ ed. Vol. 1. Oxford: Blackwell Publishing; 2004. p. 16-27.

4. Stevens DL, Bisno AL, Chambers HF, Dellinger EP, Goldstein EJ, Gorbach SL, et al. Practice guidelines for the diagnosis and management of skin and soft tissue infections: 2014 update by the infectious diseases society of America. Clin Infect Dis. 2014;59(2):e10-52. https://doi.org/10.1093/cid/ciu296

PMid:24947530

5. Mcnamara DR, Tlyjeh IM, Berbari EF, Lahr BD, Martinez J, Mirzoyev SA, et al. A predictive model of recurrent lower extremity cellulitis in a population-based cohort. Arch Intern Med. 2007;167(7):709-15. https://doi.org/10.1001/archinte.167.7.709 PMid: 17420430

6. Pavlotsky F, Amrani S, Trau H. Recurrent erysipelas: Risk factors. J Dtsch Dermatol Ges. 2004;2(2):89-95. https://doi. org/10.1046/j.1439-0353.2004.03028.x

PMid: 16279242

7. Goettsch WG, Bavinck JN, Herings RM. Burden of illness of bacterial cellulitis and erysipelas of the leg in the Netherlands. J Eur Acad Dermatol Venereol. 2006;20(7):834-9. https://doi. org/10.1111/j.1468-3083.2006.01657.x

PMid: 16898907

8. Phoenix G, Das S, Joshi M. Diagnosis and management of cellulitis. BMJ. 2012;345:e4955. https://doi.org/10.1136/bmj. e4955

\section{PMid:22872711}

9. Christensen KL, Holman RC, Steiner CA, Sejvar JJ, Stoll BJ, Schonberger LB. Infectious disease hospitalizations in the United States. Clin Infect Dis. 2009;49(7):1025-35. https://doi. org/10.1086/605562

PMid:19708796

10. NHS Digital. Hospital Episode Statistics for England 2014-15. Available from: https://www.digital.nhs.uk/catalogue/PUB19124. [Last accessed on 2017 Apr 09].

11. Australian Institute of Health and Welfare. Australian Hospita Statistics 2001-2002. Canberra: AlHW; 2003.

12. Karppelin $\mathrm{M}$, Siljander $\mathrm{T}$, Vuopio-Varkila J, Kere J, Huhtala $\mathrm{H}$, Vuento $\mathrm{R}$, et al. Factors predisposing to acute and recurrent bacterial non-necrotizing cellulitis in hospitalized patients: A prospective case-control study. Clin Microbiol Infect. 2010;16(6):729-34. https://doi. org/10.1111/j.1469-0691.2009.02906.x

PMid:19694769

13. Carratala J, Roson B, Fernandez-Sabe N, Shaw E, del Rio O, Rivera $\mathrm{A}$, et al. Factors associated with complications and mortality in adult patients hospitalized for infectious cellulitis. Eur J Clin Microbiol Infect Dis. 2003;22(3):151-7. https://doi. org/10.1007/s10096-003-0902-x

PMid: 12649712

14. Guberman D, Gilead LT, Zlotogorski A, Schamroth J. Bullous erysipelas: A retrospective study of 26 patients. J Am Acad Dermatol. 1999;41(5 Pt 1):733-7. https://doi.org/10.1016/ s0190-9622(99)70009-5 PMid: 10534636

15. Chelsom J, Halstensen A, Haga T, Hoiby EA. Necrotising fasciitis due to group A streptococci in Western Norway: Incidence and clinical features. Lancet. 1994;344(8930):1111-5. https://doi. org/10.1016/s0140-6736(94)90629-7

PMid:7934492 
16. Lazzarini L, Conti E, Tositti G, de Lalla F. Erysipelas and cellulitis: Clinical and microbiological spectrum in an Italian tertiary care hospital. J Infect. 2005;51(5):383-9. https://doi.org/10.1016/j. jinf.2004.12.010

PMid:16321649

17. Concheiro J, Loureiro M, González-Vilas D, GarcíaGavín J, Sánchez-Aguilar D, Toribio J, et al. Erysipelas and cellulitis: A retrospective study of 122 cases. Acta Dermosifiliogr. 2009;100(10):888-94. https://doi.org/10.1016/ s1578-2190(09)70560-8

PMid:20038366
18. Bartholomeeusen S, Vandenbroucke J, Truyers C Buntinx F. Epidemiology and comorbidity of erysipelas in primary care. Dermatology. 2007;215(2):118-22 https://doi. org/10.1159/000104262

PMid:17684373

19. Bjornsdottir S, Gottfredsson M, Thorisdottir AS, Gunnarsson GB, Ríkardsdóttir $\mathrm{H}$, Kristjánsson $\mathrm{M}$, et al. Risk factors for acute cellulitis of the lower limb: A prospective case-control study. Clin Infect Dis. 2005;41(10):1416-422. https://doi. org/10.1086/497127

PMid:16231251 